Unreviewed preprint of:

Thomas Krummrein, Martin Henke, Peter Kutne, Manfred Aigner Numerical analysis of operating range and SOFC-off-gas combustor requirements of a biogas powered SOFC-MGT hybrid power plant Appl. Energy. 232 (2018) 598-606

The original publication is available at www.elsevier.com

http://dx.doi.org/10.1016/j.apenergy.2018.09.166

(C) 2018. This manuscript version is made available under the CC-BY-NC-ND

4.0 license http://creativecommons.org/licenses/by-nc-nd/4.0/ 


\title{
Numerical Analysis of Operating Range and SOFC-Off-Gas Combustor Requirements of a Biogas Powered SOFC-MGT Hybrid Power Plant
}

\author{
T. Krummrein*, M. Henke, P. Kutne, M. Aigner
}

German Aerospace Center, Institute of Combustion Technology, Pfaffenwaldring 38-40, 70569 Stuttgart, Germany

\begin{abstract}
Hybrid Power plants (HyPP) combining a micro gas turbine with a solid oxide fuel cell are projected to reach very high electric efficiency values. Powered by biogas, they have the potential to become an important pillar for a future $\mathrm{CO}_{2}$-neutral energy mix. However, to compensate the fluctuating energy yield of wind turbines and photovoltaic power plants they should also provide a wide operating range. While previous numerical studies show that this is the case for natural gas powered HyPP, the impact of biogas utilization on the operating range was still unknown.

In the present study, a detailed numeric model of the HyPP being constructed at DLR is presented. The model is used for an in-depth investigation of the operating limits using biogases with various methane contents. The influence of fuel cell operating limits, like the stack temperature, minimal cell voltage and maximal fuel utilization rate, on the HyPP operation range are discussed. While the results show a strong correlation between methane content and operation range, a power output reduction of $33 \%$ is still feasible for methane contents as low as $60 \mathrm{vol} \%$.

Knowing the operating range of the HyPP is also crucial for the design of the plants components. Hence, in a final step the operating conditions for the fuel cell off-gas combustor are derived for the respective operating ranges.
\end{abstract}

Keywords: Micro gas turbines, Solid oxide fuel cell, Hybrid power plant, Biogas, Operating range, Off-gas combustor

${ }^{*}$ Corresponding author

Email address: Thomas. Krummrein@DLR.de (T. Krummrein) 


\section{Introduction}

In the face of climate change and ever stricter regulations on $\mathrm{CO}_{2}$-emissions, the need for $\mathrm{CO}_{2}$-neutral energy sources is growing. While wind power and photovoltaics are paramount for an environmental friendly energy mix of the future, their volatility puts a strong burden on energy grids [1]. Because of these fluctuations and ultimately the risk of dark doldrums, complementary power sources must be kept available [2] Power plants using biofuels can provide such a $\mathrm{CO}_{2}$ neutral power source. Those power plants must provide a wide operating range to compensate for volatile renewable power sources. Additionally, sources of biomass that do not compete with food production like wood industrial waste or landfill gas are scarce and their compositions vary over time. Hence, power plants should utilize these sources with high efficiency and must be able to handle the highly fluctuating calorific value of these fuels.

One promising candidate for such a biofuel-operated power plant is given by the combination of a micro gas turbine (MGT) with a solid oxide fuel cell (SOFC). In such a hybrid power plant (HyPP) the MGT pressurizes the SOFC and thus increases both its electrical efficiency and power output. Furthermore, the hot SOFCoff-gas contains residual fuel which is burned in a downstream combustor. The gas is then expanded in the turbine to power the compressor and further increase the power output of the HyPP. As a result, HyPP are projected to reach electrical efficiency values above $60 \%$ based on the lower heating value (LHV). In contrast to other power plants (e.g. combined gas and steam power plants), these efficiency values can be achieved with electrical power outputs smaller than $100 \mathrm{~kW}_{\mathrm{el}}$. Hence, they can be employed decentralized, wherever there is demand for waste heat. HyPP also support a wide operating range relying on natural gas [3]. Whether the same can be achieved with biogas and whether HyPP can handle the strongly fluctuating calorific value are decisive factors for the successful positioning of the technology in a future $\mathrm{CO}_{2}$-neutral energy market.

To resolve these and other related questions the DLR institutes of Combustion Technology and Engineering Thermodynamics are conducting a collaborative effort in the EU Horizon 2020 project "Bio-HyPP" [4] to build a HyPP demonstrator. It will combine an MGT producing $3 \mathrm{~kW}_{\mathrm{el}}$ with an SOFC in planar design supplying $30 \mathrm{~kW}_{\mathrm{el}}$. Supporting this endeavor, detailed numerical process simulations are done to anticipate the impact of biofuels on the HyPP in construction.

The present paper starts with a description of the

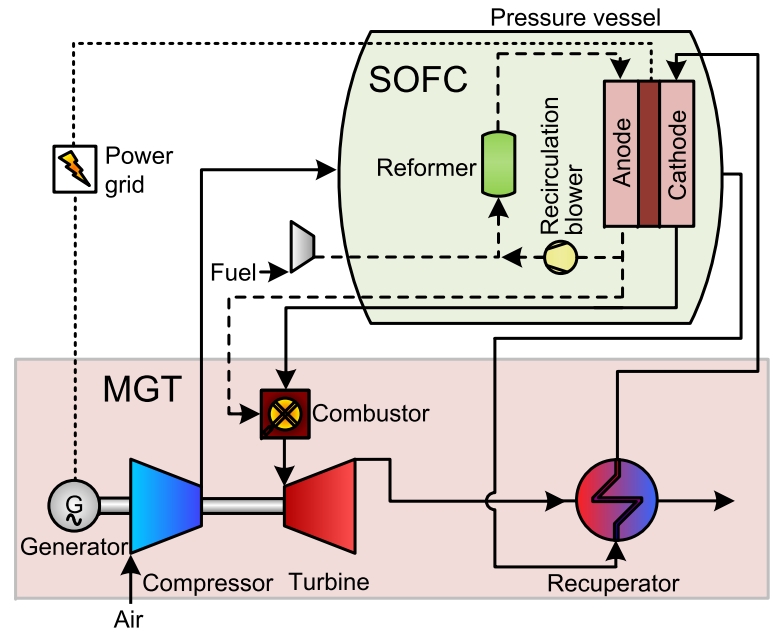

Figure 1: Structure of the HyPP demonstrator model.

HyPP demonstrator test rig, the steady-state simulation tool and the system model. This section includes a discussion of boundary conditions and special characteristics of the model. While an overview of the HyPP operating range was given already at the EFC conference in 2017 [5], here the various mechanism that limit operating range are described in more detail, again with an emphasis on the impact of biogas composition. Building on this work, the requirements for the SOFC off-gas combustor are derived and presented for the entire operating range. Knowing the accurate boundary conditions of the combustion chamber is crucial in the design process, as they differ considerably from the conditions in a conventional MGT.

\section{Simulation setup}

The impact of biogas as fuel for a HyPP is investigated with a numerical steady state model of the demonstrator which is currently being built at the DLR. Figure 1 shows the structure of the demonstrator model. It contains the components of the real demonstrator which are essential for steady state operation. Ambient air is compressed with a maximum pressure ratio of about 3 . The compressed air is first used to purge the pressure vessel which contains the SOFC stack. This ensures low pressure differences between the stack and the surrounding air. Furthermore, it prevents explosive atmospheres in case of leakages. The purging air is preheated with a recuperator and supplies the SOFC cathode. The anode of the SOFC is supplied with a mixture of fuel and recirculated anode off-gas. A reforming process reduces the hydrocarbon contents to protect the SOFC 
against coking. The use of a recirculation blower allows to set the recirculation rate. This system layout includes only one combustor. It is used to burn the anode offgas. Additionally, it can be supplied directly with fuel (not shown in Fig. 1) during the start up procedure or certain operation maneuvers. The hot exhaust gas from the combustion chamber is first expanded in the turbine which drives the compressor and the generator considering friction losses. It is then used to preheat the compressed air via the recuperator. The remaining energy of the exhaust gas can be utilized as a heat source. If a suitable heat consumer is available, about $20 \%$ of the fuel energy can be reused in this way.

Most of the electric output is produced by the SOFC with up to $30 \mathrm{~kW}_{\mathrm{el}}$. The main task of the MGT System is to provide high temperature, high pressure air for the SOFC system. However, the high temperature exhaust gas from the SOFC off-gas combustor provides enough enthalpy for the turbine to not only power the compressor but also to power a generator with a maximum output of $3 \mathrm{~kW}_{\mathrm{el}}$.

The HyPP demonstrator model was created with the in-house simulation tool Micro Gas Turbine Steady State Simulator $\left(M G T S^{3}\right)$. This is a modular Matlab/Simulink based tool which was introduced by Panne et. al. [6]. It was further developed and validated with experimental data by Henke et. al. [7]. Krummrein et. al. [8] implemented an improved solver routine which enables the detailed simulation of complex systems like HyPP.

The model represents each component and the piping with $0 \mathrm{D}$ models. It considers heat and pressure losses of all components. The heat losses are set in accordance with the work of Steilen et. al. [3]. The recuperator is modeled assuming a constant efficiency.

The SOFC stack model is developed and parameterized by experimental data from the DLR institute of Engineering Thermodynamics. The compressor and turbine are modeled by turbo maps that have been determined experimentally. These maps include the isentropic efficiency and pressure ratio for all relevant operation points.

Table 1 lists the most important boundary conditions which are used in this model configuration. The turbine outlet temperature is limited by the maximum recuperator temperature. However, a decreasing turbine outlet temperature influences the system always negative in terms of system efficiency and operation range. This is the reason why the turbine outlet temperature is specified as a constant boundary condition which is set to its maximum value of 1060 kelvin. A high recirculation of SOFC anode off-gas is advantageous to reduce

\begin{tabular}{ll}
\hline Quantity & Value \\
\hline Stack temperature & $1073 \mathrm{~K}$ to $1123 \mathrm{~K}$ \\
MGT shaft speed & $150 \mathrm{krpm}$ to $240 \mathrm{krpm}$ \\
Fuel methane content & $40 \mathrm{vol} \%$ to $100 \mathrm{vol} \%$ \\
Ambient temperature & $288 \mathrm{~K}$ \\
Ambient pressure & $1.013 \mathrm{hPa}$ \\
Fuel inlet temperature & $288 \mathrm{~K}$ \\
Turbine outlet temp. & $1060 \mathrm{~K}$ \\
Recuperator efficiency & $90 \%$ \\
Recirculation ratio & $80 \%$ \\
\hline
\end{tabular}

Table 1: Boundary conditions of HyPP model.

temperature gradients and allow lower single pass fuel utilization rates. However, very high recirculation rates impose technically difficulties. Hence, a constant recirculation rate of $80 \%$ is used for this study. However, as many technological limitations apply, the optimal value must be determined in future experimental studies.

In this configuration, the electric output of the system is not a degree of freedom. However, it correlates strongly with the MGT shaft speed which can be set directly. In contrast to a lot of SOFC system analysis approaches, the fuel utilization is also not a degree of freedom but it is determined by the fuel mass flow and the SOFC power output set-points. This will be described in more detail in the next section.

\section{Influence of Biogas on the HyPP System}

In the following, the steady state HyPP model is used to investigate the influence of biogas quality on the system. The biogas is modeled as a mixture of methane and carbon dioxide with methane contents between $40 \mathrm{vol} \%$ and $100 \mathrm{vol} \%$.

\subsection{Relations between electric output, stack tempera- ture and overall FU}

An important quantity to explain the behavior of the HYPP system is the overall fuel utilization (FU) of the SOFC. This is the FU of the SOFC including recirculation. Figure 2 shows the overall FU for two stack temperatures and different methane concentrations of the fuel in dependency of the electric output of the system. In general, the overall FU increases with decreasing power output. This is a result of the fixed turbine outlet temperature. Figure 3 explains this by looking at the distribution of the fuels energy. Also the overall FU increases with increasing stack temperature. According to the explanation of Fig. 3 this is because of the decreasing ratio $\dot{Q}_{\text {Combustor }} / \dot{Q}_{\text {SOFC }}$. 


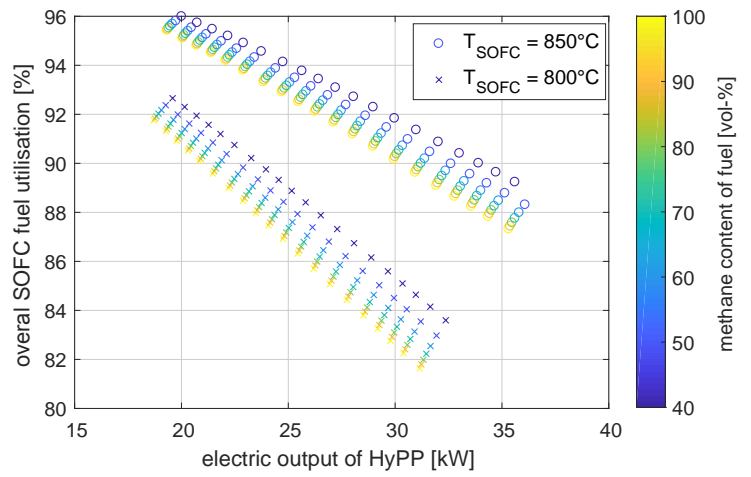

Figure 2: Overall fuel utilization of the SOFC.

\subsection{Impact Mechanisms of Biogas}

An increasing proportion of carbon dioxide in the fuel influences the system by two mechanisms: First, it increases the heat capacity flow of the fuel and therefore it cools down the SOFC. To maintain a certain stack temperature this must be compensated by a reduced air flow. This effect is further enhanced as the fuel enters the SOFC with approximately ambient temperature whereas the inlet air temperature is approximately $950 \mathrm{~K}$.

Secondly, it decreases the Nernst potential at the SOFC, as it increases the concentrations of a reaction product [9]. This effect is further amplified by the reduced air flow which increases the oxygen utilization of the air and therefore reduces the oxygen partial pressure.

Both mechanisms increase the overall FU which can be seen in Fig. 2. Further investigation of the model indicates, that the impact of the cooling mechanism is stronger than the impact of the Nernst voltage decrease.

While the impact of these effects on FU are clearly visible in Fig. 2, their influence e.g. on air mass flow is very low and hence the impact of electric output variation is much stronger.

\subsection{HyPP Process Quantites Limitations}

An important question regarding the use of biogas in a HyPP is the influence on the operating range. It is determined by several limits of process quantities [3]:

- A maximum single pass fuel utilization ratio of $70 \%$ prevents fuel starvation and increased degradation of the SOFC cells.

- The SOFC cell voltage must be above the nickel oxidation limit. Including a safety margin, the limit is set to $0.68 \mathrm{~V}$.
- A too large oxygen utilization of the air can lead to cell degradation. Therefore, it is limited here to $50 \%$.

- The ceramic components of the SOFC must be protected against too large spatial temperature gradients. Therefore, in accordance to the supplier, the temperature difference between the anode and cathode inlet must be below $150 \mathrm{~K}$, between the stack core and the anode inlet below $300 \mathrm{~K}$ and between the stack core and the cathode inlet below $250 \mathrm{~K}$. As the SOFC is represented by a ODmodel, the conservative assumption is made that stack core temperature is equal to stack outlet temperature.

- In accordance to the manufacturer the stack core temperature for steady state operations must be between $1073 \mathrm{~K}$ and $1123 \mathrm{~K}$.

- The shaft speed of the MGT must not exceed the maximum manufacturer value of $240000 \mathrm{rpm}$.

- As described before, the turbine outlet temperature must not exceed the maximum recuperator temperature of $1060 \mathrm{~K}$.

In the following, the influence of biogas as fuel to these operation limits is investigated. The analysis was done for stack temperatures of $1073 \mathrm{~K}$ and $1125 \mathrm{~K}$ to highlight the impact of stack temperature variation and the operation limits caused by stack temperature limits.

\subsubsection{Single Pass Fuel Utilization}

Figure 4 shows the single pass FU of the SOFC for a recirculation ratio of $80 \%$. For a constant recirculation ratio the relation between the overall $\mathrm{FU}$ and the single pass FU is monotonous. Therefore, the behavior of the single pass FU is very similar to the overall FU described above. It can be seen that for high stack temperatures and low electric output the single pass fuel utilization limit is exceeded. It is possible to reduce the single pass fuel utilization maintaining the overall SOFC system fuel utilization by increasing the recirculation ratio. However, this is only possible within certain limits, since an excessive recirculation ratio causes too large pressure drops and pressure differences or is technically impracticable. Therefore, in the following the recirculation ratio will remain at a constant value of $80 \%$.

By analogy to the investigation of overall FU, an increasing carbon dioxide content of the fuel increases the single pass fuel utilization only slightly. Again, fig. 4 


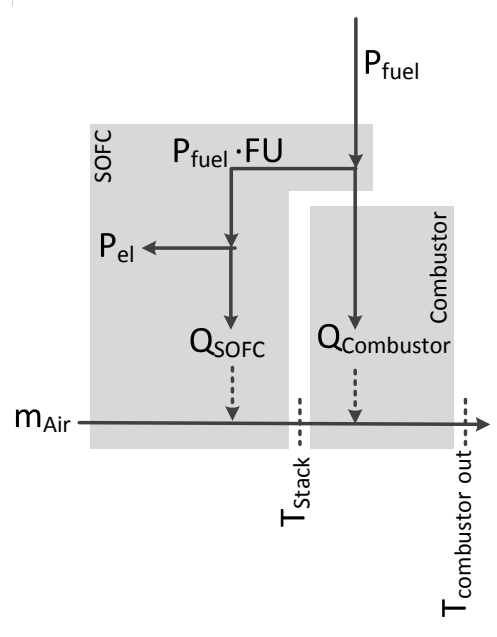

I. Assume constant combustor outlet temperature:

1. Electric output of SOFC $P_{\mathrm{el}}$ is decreased.

2. According to the UI-curve [9]: Cell voltage $U_{\text {cell }}$ increases, current $I$ decreases.

3. With $P_{\mathrm{el}}=U_{\text {cell }} \cdot I$ : The relative decrease of $I$ is stronger than the relative decrease of $P_{\mathrm{el}}$.

4. The fuel consumed by the SOFC $P_{\text {fuel }} \cdot F U$ decreases proportional to $I$.

5. It is $P_{\text {el }}+\dot{Q}_{\text {SOFC }}=P_{\text {fuel }} \cdot F U$. Since the relative decrease of $P_{\text {fuel }} \cdot F U$ is stronger than the relative decrease of $P_{\mathrm{el}}$, the relative decrease of $\dot{Q}_{\mathrm{SOFC}}$ must be even stronger than the relative decrease of $P_{\text {fuel }} \cdot F U$.

6. The heat capacity flow of the fuel flow is small compared to the heat capacity flow of the air flow. Also, the temperature of the preheated air flow varies little. Therefore, to maintain the stack temperature, the air flow must decrease according to the decrease of $\dot{Q}_{\text {SOFC. }}$.

7. With decreasing air flow the combustor power $\dot{Q}_{\text {Combustor }}$ must decrease to maintain the constant combustor outlet temperature. The relative decrease is approximately the same as for $\dot{Q}_{\mathrm{SOFC}}$.

8. From points 5. and 7. follow: $P_{\text {fuel }} \cdot F U$ and $\dot{Q}_{\text {Combustor }}$ has to decrease, but the relative decrease of $\dot{Q}_{\text {Combustor }}$ is stronger.

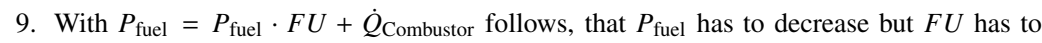
increase.

II. Consider variation of combustor outlet temperature:

10. MGT shaft speed decreases because of reduced air flow.

11. Pressure ratio of system decreases.

12. Combustor outlet temperature decreases to maintain a constant turbine outlet temperature.

13. $\dot{Q}_{\text {Combustor }}$ has to decrease further. Therefore, the increase of $F U$ is amplified.

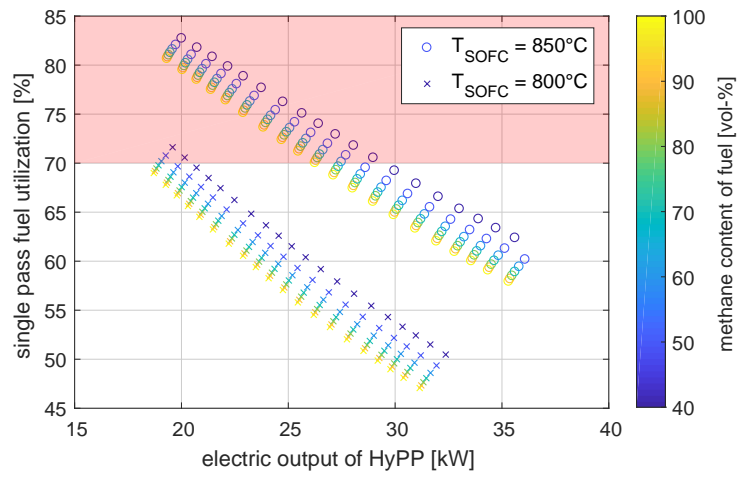

Figure 4: Single pass fuel utilization of the SOFC at a recirculation ratio of $80 \%$

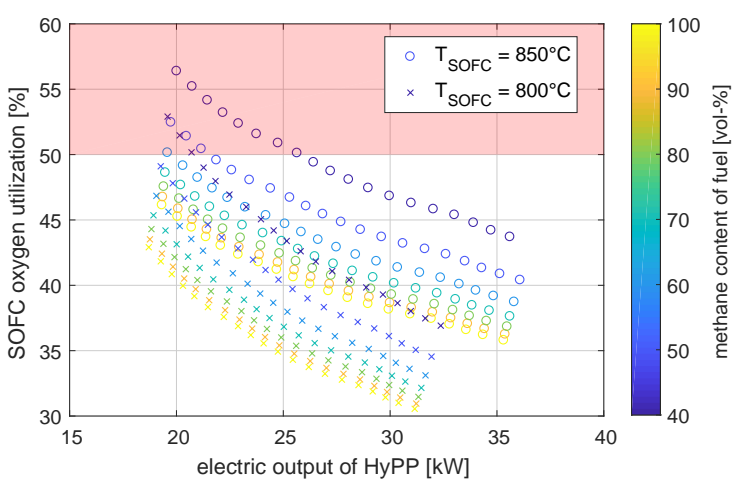

Figure 5: Oxygen utilization of the SOFC.

shows that the effect is minor in comparison to the electric output variation over a typical operating range.

\subsubsection{Oxygen Utilization}

As described above, the cooling effect of the additional carbon dioxide in the fuel results in a lower air mass flow and therefore an increased oxygen utilization. In contrast to the rather small effect on FU, oxygen 


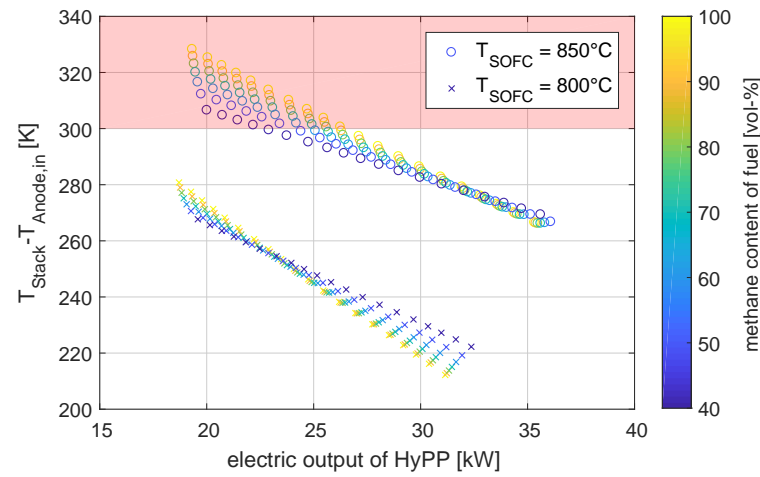

Figure 6: Temperature difference between stack and anode inlet at a recirculation rate of $80 \%$

utilization changes over the methane content range in a similar manner as it does over the electric output range.

Figure 5 shows that the air utilization for a fuel with a methane content of 40 vol\% is increased by approximately $25 \%$ compared to pure methane. Also, for methane lean fuels the air utilization limit is exceeded for low electric outputs.

\subsubsection{SOFC Temperature Differences}

The mixture of recirculated anode off-gas and fuel is reformed before the anode inlet. The reforming process reduces the methane content of the anode inlet flow to avoid coking. However, the endothermic process also reduces the temperature, in particular for low mass flow rates at small recirculation rates. Figure 6 shows that with a stack temperature of $1123 \mathrm{~K}$ and pure methane the maximum temperature difference between the stack core and the anode inlet flow is exceeded below a critical electric output of approximately $27 \mathrm{~kW}$. Lower stack temperatures reduce the critical electric output significantly. The fuel composition has only a very small impact on the critical electric output but methane lean fuels shows a slightly decreased critical electric output.

An exceeding of the other temperature difference limits described above is not observed.

\subsubsection{MGT Shaft Speed}

The shaft speed of the MGT determines the air mass flow and the pressure ratio of the system. Therefore, low stack temperatures and large electric outputs increase the shaft speed. The maximum electric output of the HyPP demonstrator is reached at the maximum shaft speed of $240000 \mathrm{rpm}$. Figure 7 shows that for a stack temperature of $1123 \mathrm{~K}$ this maximum is about $35 \mathrm{~kW}$.

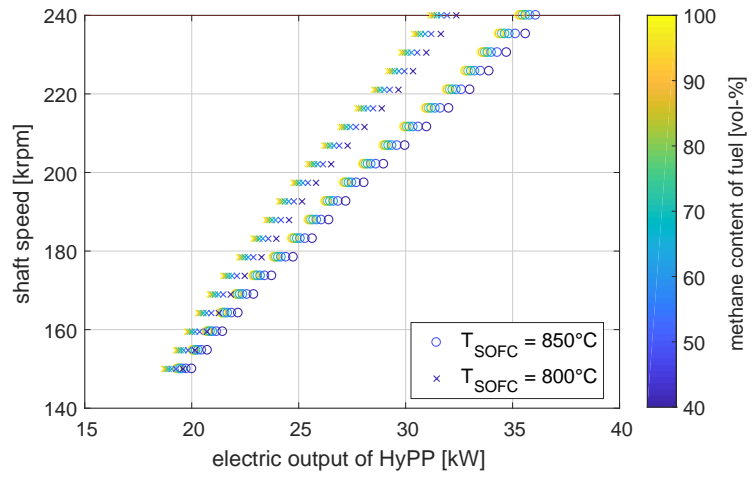

Figure 7: Shaft speed of the MGT.

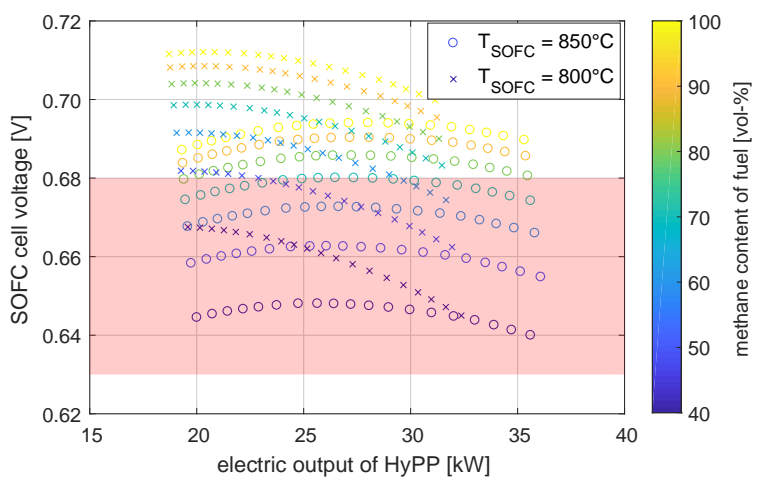

Figure 8: Cell voltage of the SOFC.

The cooling effect of carbon dioxide in the fuel results in a slightly reduced air mass flows. Therefore, the shaft speed for methane lean fuels is slightly decreased. Again, the impact of fuel composition variation is small compared to the impact of a variation in electric output.

\subsubsection{SOFC Cell Voltage}

Compared to the previous examples, the reduction of SOFC cell voltage due to decreasing fuel methane content has the most significant implication on the HyPP operation range. While a reduction of methane content to 80 vol\% does not reduce operation range, fig. 8 shows that further reductions lead to an over-proportional voltage drop and a narrowing of operation limits. It is also interesting to note that this sensitivity is more pronounced than the sensitivity of the electric output on cell voltage.

A slight reduction of the minimal SOFC cell voltage limit below $0.68 \mathrm{~V}$ might be acceptable. However, an investigation of the related trade-off is not part of this 


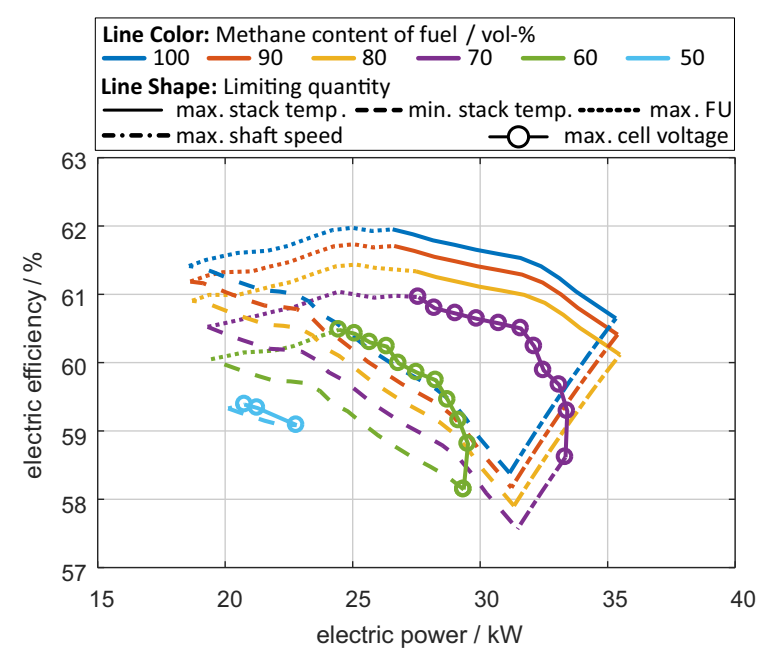

Figure 9: Operating range for the HyPP demonstrator for different methane concentrations of the fuel and a recirculation ratio of $80 \%$.

study.

\subsection{System Operating Range}

Figure 9 summarizes the behavior of the previously described quantities to the expected operating range of the HyPP demonstrator. It shows the overall electric LHV-based efficiency of the system over the electric output.

The different line colors express the different methane concentrations of the fuel, the line types determine the most limiting quantity. It can be seen that the oxygen utilization and the stack temperature differences has no impact on the operating range. Furthermore, for methane rich fuels the SOFC cell voltage limit is no restriction. For these fuels, the operating range is limited towards large electric outputs by the maximum shaft speed and the maximum stack temperature. Towards small electric outputs the operating range is limited by the maximum single pass fuel utilization and the minimum stack temperature.

However, with decreasing methane concentration of the fuel the maximum stack temperature limit and the fuel utilization limit are replaced by the cell voltage limit as most restrictive quantity. This results in a substantial reduction of the operating range. As described above, for methane contents below about $50 \mathrm{vol} \%$ no operation is possible considering the defined limits.

The impact of fuel methane concentration to the relevant thermodynamic properties of the system is rather small. Therefore, the impact to the system efficiency is

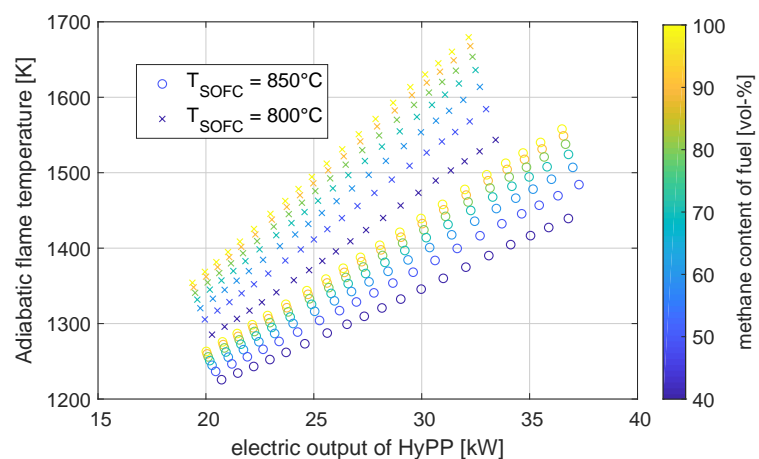

Figure 10: Adiabatic flame temperature of combustin with an cathode off-gas split of $20 \%$.

also small as shown in fig. 9. With a methane concentration of $80 \mathrm{vol} \%$ the maximum reachable electric efficiency decreases by about 0.6 percent points compared with pure methane.

As a lower cell voltage limit might be possible, a small study was done to investigate the performance with a methane content of $40 \mathrm{vol} \%$ neglecting the fuel cell voltage limit. In this case system efficiency at a stack temperature of $1123 \mathrm{~K}$ decreases by about 3.5 percent points in comparison to pure methane.

\section{Influence of Biogas on the Combustion System}

The previous section shows that the fuels methane content influences most thermodynamic process variables of the HyPP only slightly. However, some of them change significantly. This includes the combustion chamber inlet. Therefore, in this section some general requirements on a HyPP combustion chamber supplied with biogas are investigated.

The heat capacity of carbon dioxide and air or exhaust gas is nearly the same. Therefore, the decrease of air mass flow caused by the increasing concentration of carbon dioxide in the fuel is approximately equal to the additional carbon dioxide mass flow of the fuel.

For a fixed electric output, decreasing the methane content of the fuel from $100 \mathrm{vol} \%$ to $40 \mathrm{vol} \%$ reduces the combustion chamber outlet mass flow by less than $5 \%$. The heating power of the combustion system is reduced by about $10 \%$ while the combustion chamber outlet temperature is changed by less than $5 \mathrm{~K}$.

However, while the conditions at the combustion chamber outlet are only slightly affected by the use of biogas, the impact on the inlet conditions is stronger. In 


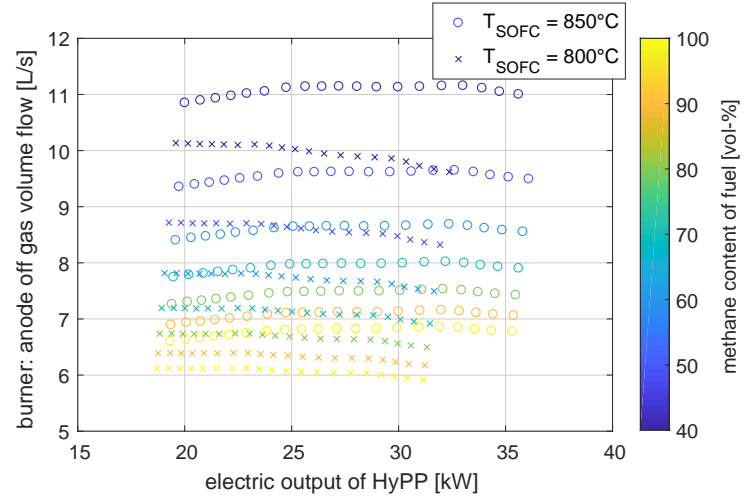

Figure 11: Volume flow of anode off gas to combustion chamber.

a typical MGT/HyPP combustion system only a part of the air is used for the actual combustion process while the bigger part is mixed downstream with the combustion exhaust gases. The percentage of air that will be used in the combustion is given by the "off-gas split" value. A lower off-gas split allows for higher adiabatic flame temperatures and therefore more stable combustion while maintaining temperature limits of the combustion system outlet. Therefore, the cathode off-gas split is an important combustion system design quantity to achieve a stable combustion with low emissions.

Figure 10 shows the adiabatic flame temperature with an exemplary cathode off-gas split of $20 \%$. Remarkable are the quite low adiabatic flame temperatures: In a conventional MGT process with biogas, a combustion chamber with the same air split value will reach adiabatic flame temperatures between $1900 \mathrm{~K}$ and $2250 \mathrm{~K}$. This is a result of the high heating value of biogas compared to the very low one of SOFC anode off-gas. Combustion systems for methane supplied HyPP exists. However, while the adiabatic flame temperatures are even quite low for methane utilization, an additional decrease due to the use of biogas might make an adjustmant of the off-gas split unavoidable.

In the combustor the fuel flows through nozzles to achieve an higher momentum. Figure 11 shows, that decreasing the methane content of the fuel can increase the anode off-gas volume flow up to about $65 \%$. Too low volume flows can result in instable combustion while too large volume flows result in large pressure drops, which can lead to intolerable pressure difference between the SOFC anode and cathode sides. Therefore, it seems rather difficult to use the same nozzle geometry and number with methane lean fuels as well as with methane rich fuels. However, this functionality may be achieved by a more complex staggered combustion system.

Summarized, the combustion chamber inlet conditions for biogas utilization differs significantly from the ones with pure methane as fuel in terms of absolute numbers, but much less with stack temperature or system power output variations. Therefore, it seems plausible that a HyPP combustion system, which works with methane rich fuels, can be easily adapted to a fuel with a lower methane content. However, to design a combustion system which works well with methane rich and lean fuels might impose a much harder challenge.

\section{Conclusions and Outlook}

This paper investigates the impact of the use of biogas as fuel for the DLR SOFC/MGT hybrid power plant demonstrator. For this purpose, a numerical steady state model is built with the MGTS $^{3}$ tool. Simulating this model, many mechanisms are identified and discussed, some of which limit the operating range of the system. The influence of biogas is analyzed using fuel with methane concentration between $40 \mathrm{vol} \%$ and $100 \mathrm{vol} \%$.

The results show that the general thermodynamic process values and the SOFC electric efficiency are only slightly influenced by the change from methane to biogas. Therefore, at the same operation point in terms of stack temperature and electric system output, the electric efficiency of the system with a $40 \mathrm{vol} \%$ methane containing fuel reduces only about 3.5 percent points (LHV based) compared to pure methane as fuel. However, some system quantities are stronger influenced by methane lean biogases. An important example is the decrease of the SOFC cell voltage: For methane concentrations below about $50 \mathrm{vol} \%$ it falls below its minimum limit of $0.68 \mathrm{~V}$ for all operation points. Furthermore, fuels with methane concentrations below about $80 \mathrm{vol} \%$ reduce the operating range already significantly. The reduction is caused by several mechanisms that are described in detail.

In addition, the general impact of biogas on the offgas combustion system is investigated. The increased amount of inert gases in the anode off-gas as well as the reduced oxygen concentration in the cathode offgas must be considered in the combustion system design. The simulation indicates, that a stable combustion for all investigated fuel methane contents is realizable. However, the combustion chamber must probably be designed for a more narrow range of methane contents than the investigated one. It seems challenging to design a single combustion chamber that is suitable 
for all methane concentrations ranging from $40 \mathrm{vol} \%$ to 100 vol\%.

The HyPP demonstrator currently being built at the DLR will be used in future work to validate the simulation model. This work will also show whether the minimum cell voltage limit can be further reduced without a heavy impact on SOFC degradation, to allow for lower methane contents. Further research activities concern the combustion system. These will investigate the stability range for methane content variations and possibly also adapted combustion chamber designs.

\section{Acknowledgments}

The authors would like to thank their colleagues of the DLR Institute of Engineering Thermodynamics for many fruitful discussions and their support. Special thanks go to Mike Steilen for providing the SOFC stack model, Timo Lingstädt for his valuable comments on the combustion system and as well as for the whole DLR Bio-HyPP project team for their support.

This project has received funding from

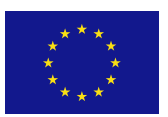
the European Union's Horizon 2020 research and innovation programme under grant agreement No 641073 (www.bio-hypp.eu).

\section{Literature}

\section{References}

[1] M. Anvari, G. Lohmann, M. Wächter, P. Milan, E. Lorenz, D. Heinemann, M. R. R. Tabar, J. Peinke, Short term fluctuations of wind and solar power systems, New Journal of Physics 18 (6) (2016) 063027.

[2] C. Zöphel, S. Schreiber, T. Müller, D. Möst, Which flexibility options facilitate the integration of intermittent renewable energy sources in electricity systems?, Current Sustainable/Renewable Energy Reports (2018) 1-8.

[3] M. Steilen, C. Salettia, M. P. Heddrich, K. A. Friedrich, Analysis of the in influence of heat transfer on the stationary operation and performance of a solid oxide fuel cell/gas turbine hybrid power plant 211 479-491. doi:10.1016/j.apenergy.2017.11.038.

URL https://doi.org/10.1016/j.apenergy.2017.11. 038

[4] European Union's Horizon 2020 research and innovation programme: Biogas-fired Combined Hybrid Heat and Power Plant (2015-2019). URL http: //www . bio-hypp.eu/

[5] T. Krummrein, Numerical analysis of a biogas powered hybrid MGT-SOFC power plant, in: Proceedings of the 7th european fuel cell Piero Lunghi conference, no. EFC17157, 2017, pp. 267-268.

URL http://www.europeanfuelcell.it/images/ proceedings_EFC17.pdf

[6] T. Panne, A. Widenhorn, J. Boyde, D. Matha, V. Abel, M. Aigner, Thermodynamic process analyses of SOFC/GT hybrid systems, in: 5th International Energy Conversion Engineering Conference and Exhibit (IECEC), no. AIAA 2007-4833, 2007. doi: 10.2514/6.2007-4833.

[7] M. Henke, T. Monz, M. Aigner, Inverted brayton cycle with exhaust gas recirculation - a numerical investigation 135 (9) (2013) 091203-1 - 091203-7. doi:10.1115/1.4024954. URL https : //doi.org/10.1115/1.4024954

[8] T. Krummrein, M. Henke, P. Kutne, A highly flexible approach on the steady-state analysis of innovative micro gas turbine cycles, in: Proceedings of ASME Turbo Expo 2018: Turbomachinery Technical Conference and Exposition (GT 2018), no. GT201875664, 2018.

[9] J. Larminie, A. Dicks, Fuel Cell Systems Explained, 2nd Edition, Wiley. 